\title{
Nasal high-flow oxygen therapy system for improving sleep-related hypoventilation in chronic obstructive pulmonary disease: a case report
}

\author{
Miyuki Okuda ${ }^{*}$, Makoto Kashio', Nobuya Tanaka², Tomoshige Matsumoto', Sumiko Ishihara ${ }^{3}$, Tatsuo Nozoe ${ }^{4}$,
} Takashi Fujii ${ }^{1}$, Yoshinari Okuda ${ }^{5}$, Toshiomi Kawahara ${ }^{6}$ and Keigo Miyata ${ }^{7}$

\begin{abstract}
Introduction: Sleep-related hypoventilation should be considered in patients with chronic obstructive pulmonary disease, because appropriate respiratory management during sleep is important for preventing elevation of $\mathrm{PaCO}_{2}$ levels. A nasal high-flow oxygen therapy system using a special nasal cannula can deliver suitably heated and humidified oxygen at up to $60 \mathrm{~L} / \mathrm{min}$. Since the oxygen concentration remains a constant independent of minute ventilation, this system is particularly useful in patients with chronic obstructive pulmonary disease who have hypercapnia. This is the first report of sleep-related hypoventilation with chronic obstructive pulmonary disease improving using a nasal high-flow oxygen therapy system.
\end{abstract}

Case presentation: We report the case of a 73-year-old Japanese female who started noninvasive positive-pressure ventilation for acute exacerbation of chronic obstructive pulmonary disease and $\mathrm{CO}_{2}$ narcosis due to respiratory infection. Since she became agitated as her level of consciousness improved, she was switched to a nasal high-flow oxygen therapy system. When a repeat polysomnography was performed while using the nasal high-flow oxygen therapy system, the Apnea Hypopnea Index was 3.7 times/h, her mean $\mathrm{SpO}_{2}$ had increased from 89 to 93\%, percentage time with $\mathrm{SpO}_{2} \leq 90 \%$ had decreased dramatically from 30.8 to $2.5 \%$, and sleep stage 4 was now detected for 38.5 minutes. As these findings indicated marked improvements in sleep-related hypoventilation, nasal high-flow oxygen therapy was continued at home. She has since experienced no recurrences of $\mathrm{CO}_{2}$

narcosis and has been able to continue home treatment.

Conclusions: Use of a nasal high-flow oxygen therapy system proved effective in delivering a prescribed concentration of oxygen from the time of acute exacerbation until returning home in a patient with chronic obstructive pulmonary disease, dementia and sleep-related hypoventilation. The nasal high-flow oxygen therapy system is currently used as a device to administer high concentrations of oxygen in many patients with type I respiratory failure, but may also be useful instead of a Venturi mask in patients like ours with type II respiratory failure, additionally providing some positive end-expiratory pressure.

Keywords: Nasal high-flow oxygen therapy, Sleep-related hypoventilation, Chronic obstructive pulmonary disease

\footnotetext{
* Correspondence: ryoheikunn@msf.biglobe.ne.jp

'Osaka Hospital, Internal Medicine Department, Neyagawakoen 2276-1,

Neyagawa City, Osaka 572-0854, Japan

Full list of author information is available at the end of the article
} 


\section{Introduction}

Sleep-related hypoventilation (SRH) should be considered in patients with chronic obstructive pulmonary disease (COPD), because appropriate respiratory management during sleep is important in preventing elevations in $\mathrm{PaCO}_{2}$ levels. Variations in minute ventilation must be considered in the respiratory management of COPD, and the oxygen delivery system used should be capable of high flow rates in which fractional inspired oxygen concentrations $\left(\mathrm{FiO}_{2}\right)$ do not vary with the patient's breathing pattern. We have previously reported that the average volume-assured pressure support (AVAPS) ventilatory mode was useful in achieving target minute ventilation in a patient with acute exacerbation of COPD who had sleep-disordered breathing.

We report herein the case of a patient in whom a nasal high-flow oxygen therapy system (NHFOTS; PacificMedico, Tokyo, Japan) and a biphasic positive airway pressure (BiPAP) machine (Vivo 30; Breas Medical AB, Mölnlycke, Sweden) were used for acute management of COPD. The patient was able to be weaned from noninvasive positive-pressure ventilation (NPPV), achieved improvements in $\mathrm{SRH}$, and was subsequently able to be treated at home.

\section{Case presentation}

A 73-year-old Japanese female was being treated by a local physician for hypertension, depression, dementia and insomnia. She developed flu-like symptoms in December 2013, and was diagnosed with influenza/cold by her physician. Clarithromycin (CAM) was prescribed. The next day, her level of consciousness decreased, so she was transported to an urgent care facility. Marked hypoxemia and hypercapnia were then identified, and she was transferred to our hospital for further evaluation and treatment.

She had an axillary temperature of $37.2^{\circ} \mathrm{C}$, a heart rate of 82 beats/min and regular, a respiratory rate of 14 breaths/ min (tachypneic), a blood pressure of $156 / 86 \mathrm{mmHg}$, and peripheral oxygen saturation $\left(\mathrm{SpO}_{2}\right)$ of $79 \%$ (with nasal oxygen at $2 \mathrm{~L} / \mathrm{min})$. Her level of consciousness was decreased (Glasgow Coma Scale: eye opening 4, verbal response 3 , motor response 5 , total 12 ), but no pallor or icterus was evident.

Her radiography revealed cardiomegaly and increased transparency of the upper lung fields bilaterally, indicating emphysema. Her echocardiography revealed a mild decrease in left ventricular ejection fraction (56\%), right atrial and ventricular enlargement, and an estimated pulmonary systolic blood pressure of $57 \mathrm{mmHg}$, indicating moderate pulmonary hypertension.

Respiratory management for type II respiratory failure was started with NPPV (ST mode; inspiratory positive airway pressure $10 \mathrm{cmH}_{2} \mathrm{O}$; expiratory positive airway pressure $4 \mathrm{cmH}_{2} \mathrm{O}$; ventilation rate 18 breaths/min; $\mathrm{FiO}_{2}$
$30 \%)$. For right-sided heart failure with pulmonary hypertension (clinical scenario, CS5), diuretics and a nitrite were started. Hypercapnia gradually improved, but as her level of consciousness improved, she became more agitated and delirious due to dementia, and management by mask became impossible. She was therefore switched to a NHFOTS (oxygen, $5 \mathrm{~L} / \mathrm{min}$; continuous positive airway pressure (CPAP), $8 \mathrm{cmH}_{2} \mathrm{O}$ ).

No recurrence of $\mathrm{CO}_{2}$ narcosis was seen subsequently, and hypoxemia improved $\left(\mathrm{SpO}_{2}, 94-96 \%\right)$. Using the NHFOTS with a high flow rate, respiratory management was able to be continued without any further agitation. Her arterial blood gases (ABGs) were: $\mathrm{pH}$ 7.47, $\mathrm{PaO}_{2}$ $57 \mathrm{mmHg}, \mathrm{PaCO}_{2} 62 \mathrm{mmHg}$, and $\mathrm{HCO}_{3}{ }^{-} 41.5 \mathrm{mmol} / \mathrm{L}$.

Investigation of SRH by polysomnography (PSG) showed an apnea-hypopnea index (AHI) of 12.1 events/h, and SRH was therefore diagnosed. When a repeat PSG was performed while using the NHFOTS, her AHI was 3.7 events/h, her mean $\mathrm{SpO}_{2}$ had increased from 89 to $93 \%$, the percentage time with $\mathrm{SpO}_{2} \leq 90 \%$ had decreased dramatically from 30.8 to $2.5 \%$, and sleep stage 4 (deep sleep), which previously had not been observed, was now detected for 38.5 minutes. These results indicated marked improvements in SRH (Table 1).

Pulmonary function testing revealed severe obstructive ventilatory impairment and decreased pulmonary diffusion capacity. Based on the above test results, her classification as grade 3 on the modified Medical Research Council scale for exertional dyspnea, and her decreased percentage-predicted forced expiratory volume in one second, she was diagnosed with category D COPD, based on the Global Initiative for Chronic Obstructive Lung

Table 1 Polysomnography data for before nasal highflow therapy system and nasal high-flow therapy system

\begin{tabular}{lll}
\hline & Before NHFOTS & NHFOTS \\
\hline $\mathrm{AHI}$ (events/h) & 12.1 & 3.7 \\
$\mathrm{Al}$ (events/h) & 0.26 & 0.0 \\
$\mathrm{HI}$ (events/h) & 11.9 & 3.7 \\
Mean SpO 2 \%) & 89 & 93.0 \\
Minimum SpO $(\%)$ & 63 & 79 \\
CT90 (\%) & 30.8 & 2.5 \\
Sleep Stage 1 (min) & 109.5 & 65.0 \\
Sleep Stage 2 (min) & 210.5 & 268.0 \\
Sleep Stage 3 (min) & 68.0 & 84.0 \\
Sleep Stage 4 (min) & 0.0 & 38.5 \\
Sleep Stage REM (min) & 72.0 & 85.5 \\
\hline
\end{tabular}

NHFOTS: nasal high-flow therapy system.

AHI: apnea-hypopnea index.

Al: apnea index.

$\mathrm{HI}$ : hypopnea index.

$\mathrm{SpO}_{2}$ : Oxygen Saturation of Arterial Blood Measured by Pulse Oximeter. CT90: cumulative time percentage with $\mathrm{SpO} 2<90 \%$.

REM: Rapid eye movement. 
Disease (GOLD) guidelines, and also with SRH. She was discharged, and NHFOTS was started at home. As of the time of writing, she is continuing treatment with the NHFOTS at home, has shown no increases in $\mathrm{PaCO}_{2}$ (her ABGs as of: pH 7.46, $\mathrm{PaO}_{2} 85 \mathrm{mmHg}, \mathrm{PaCO}_{2} 41 \mathrm{mmHg}$, $\mathrm{HCO}_{3}{ }^{-} 29.2 \mathrm{mmol} / \mathrm{L}$ ), and is being followed up on.

\section{Discussion}

A wide range of evidence has shown that NPPV offers an effective treatment for acute exacerbations of COPD [1-3]. The GOLD guidelines also recommend NPPV, since this method helps to avoid intubation, removes the risk of nosocomial infections such as pneumonia during intubated mechanical ventilation, and is effective in reducing mortality rates [4]. In addition, we have previously reported that the AVAPS mode was useful in achieving target minute ventilation in a patient with acute exacerbation of COPD who had sleep-disordered breathing [5]. However, a key disadvantage of NPPV is that the method is highly reliant on patient cooperation.

Our patient had dementia due to sequelae from a previous subarachnoid hemorrhage and stroke, as well as agitation, depression and disturbance of sleep. She was taking medications prescribed by her previous physician including quetiapine, triazolam, flunitrazepam, etizolam, sulpiride and duloxetine. In such patients, continuous NPPV can be difficult, and use of a NHFOTS with a nasal cannula rather than a face mask can prove effective. We therefore switched ventilatory support devices. The American Thoracic Society states that nasal high-flow oxygen therapy using suitably warmed and humidified oxygen represents a second-line option for oxygen delivery. The NHFOTS uses a special nasal cannula and heated humidifier and can deliver oxygen at maximum flow rates of 30 to $60 \mathrm{~L} / \mathrm{min}$. Appropriate heating and humidification $\left(37^{\circ} \mathrm{C}\right.$, $100 \%$ relative humidity) significantly enhances mucociliary clearance without causing nasal discomfort [6].

In our patient, we used a PMH-2000 heated humidifier (Pacific-Medico), a number 2 nasal cannula, and a Vivo 30 ventilator (Breas Medical $A B$ ), which uses a blower assembly to deliver high flow rates (Figure 1). This system enables nasal delivery of oxygen at high concentrations and high flow rates. The advantages of a NHFOTS are that patients can still eat and converse, oral care is possible, there is less of an oppressive feeling compared to wearing a mask, and patient quality of life is improved [7]. In our patient with dementia and agitation NHFOTS, unlike NPPV, was able to be continued. Nasal high-flow oxygen therapy, mainly using a nasal highflow cannula (Optiflow ${ }^{\text {tm }}$; Fisher \& Paykel Healthcare,

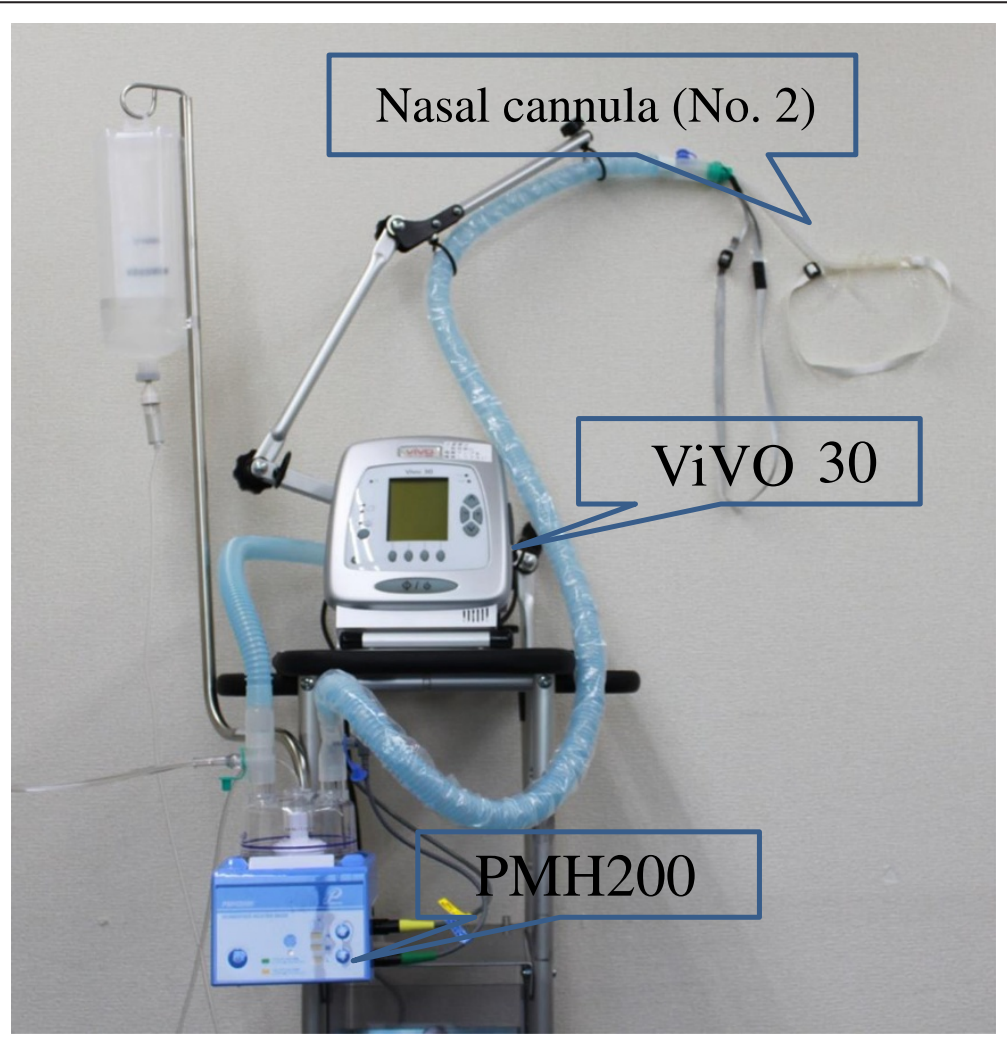

Figure 1 Equipment used for the nasal high-flow oxygen therapy system. We used a PMH-2000 heated humidifier, number 2 nasal cannula and Vivo 30 ventilator, which uses a blower assembly to deliver high flow rates. 
Auckland, New Zealand), is used worldwide and has frequently been reported in the literature.

Parke et al. compared a NHFOTS and a face mask at an oxygen flow rate of $35 \mathrm{~L} / \mathrm{min}$ in 15 patients after cardiac surgery [8]. They reported that with the mouth closed, mean airway pressure was higher with the NHFOTS $\left(2.7 \mathrm{cmH}_{2} \mathrm{O}\right)$ than with the face mask $\left(0.2 \mathrm{cmH}_{2} \mathrm{O}\right)$ [8]. A nasal high-flow cannula, compared to other oxygen delivery devices to date, can deliver nasal oxygen at very high flow rates of up to $60 \mathrm{~L} / \mathrm{min}$.

Figure 2 shows the relationship between different oxygen flow rates and $\mathrm{FiO}_{2}$ with the NHFOTS we used. With an oxygen flow rate of $30 \mathrm{~L} / \mathrm{min}$, when oxygen is supplied at $1 \mathrm{~L} / \mathrm{min}$, the $\mathrm{FiO}_{2}$ is $24.4 \%$. This is equivalent to using a $24 \%$ Venturi mask. Although greater leakage is seen with this device, since a pressure of $8 \mathrm{cmH}_{2} \mathrm{O}$ is applied, some PEEP (positive end-expiratory pressure) effect is also seen in comparison to a Venturi mask. When $2.5 \mathrm{~L} / \mathrm{min}$ of oxygen is supplied, the $\mathrm{FiO}_{2}$ is $28.5 \%$, similar to that with a 28\% Venturi mask. In England, the guidelines for oxygen therapy in acute COPD patients recommend using a Venturi mask, in which by setting the maximum inspiratory flow above the tidal volume of the patient, an accurate oxygen concentration can be delivered independent of the patient's minute ventilation [9].

With Venturi masks, many types of devices are needed, depending on the oxygen concentration delivered and due to the need for high flow rates. As a result, use of these masks is associated with several disadvantages, including high noise levels, facial and eye irritation, impaired ability to speak and inconvenience for patients when eating. A NHFOTS, by compensating for these disadvantages and using a high-flow oxygen blender, can deliver oxygen at high flow rates up to $60 \mathrm{~L} / \mathrm{min}$. With nasal high-flow oxygen therapy using a Vivo ventilator, by supplying oxygen at a maximum flow of $15 \mathrm{~L} / \mathrm{min}$, a $70 \%$ oxygen concentration can be achieved, even higher than with a conventional Venturi mask (Figure 2). By increasing CPAP to 8,13 or $20 \mathrm{cmH}_{2} \mathrm{O}$, oxygen flow rates can be increased to 30,40 and 50L/ min, respectively. Therefore, unlike a Venturi mask, a NHFOTS can even be used in patients with high minute volumes, such as those who have interstitial lung disease. It is important to understand that by increasing CPAP, the oxygen concentration is decreased even at the same oxygen flow rate (Figure 2). Specifically, for every $1-\mathrm{L} / \mathrm{min}$ increase in oxygen, oxygen concentration increases by $3.36 \%(30 \mathrm{~L} / \mathrm{min}), 2.56 \%(40 \mathrm{~L} / \mathrm{min})$ and $2.03 \%(50 \mathrm{~L} / \mathrm{min})$.

The results from the PSG in our patient confirmed the presence of sleep apnea syndrome (SAS) with an AHI of 12.1 events/h. This type of SRH can be dramatically improved using a NHFOTS during sleep (Table 1), because although the oxygen concentration is low with oxygen supplied at $1.5 \mathrm{~L} / \mathrm{min}$, the high flow system has a supply flow rate $\geq 30 \mathrm{~L} / \mathrm{min}$ that, by exerting positive pressure, improves sleep-disordered breathing.

Many factors are involved in the mechanisms of sleeprelated alveolar hypoventilation in COPD [10]. Since breathing in COPD patients is highly dependent on

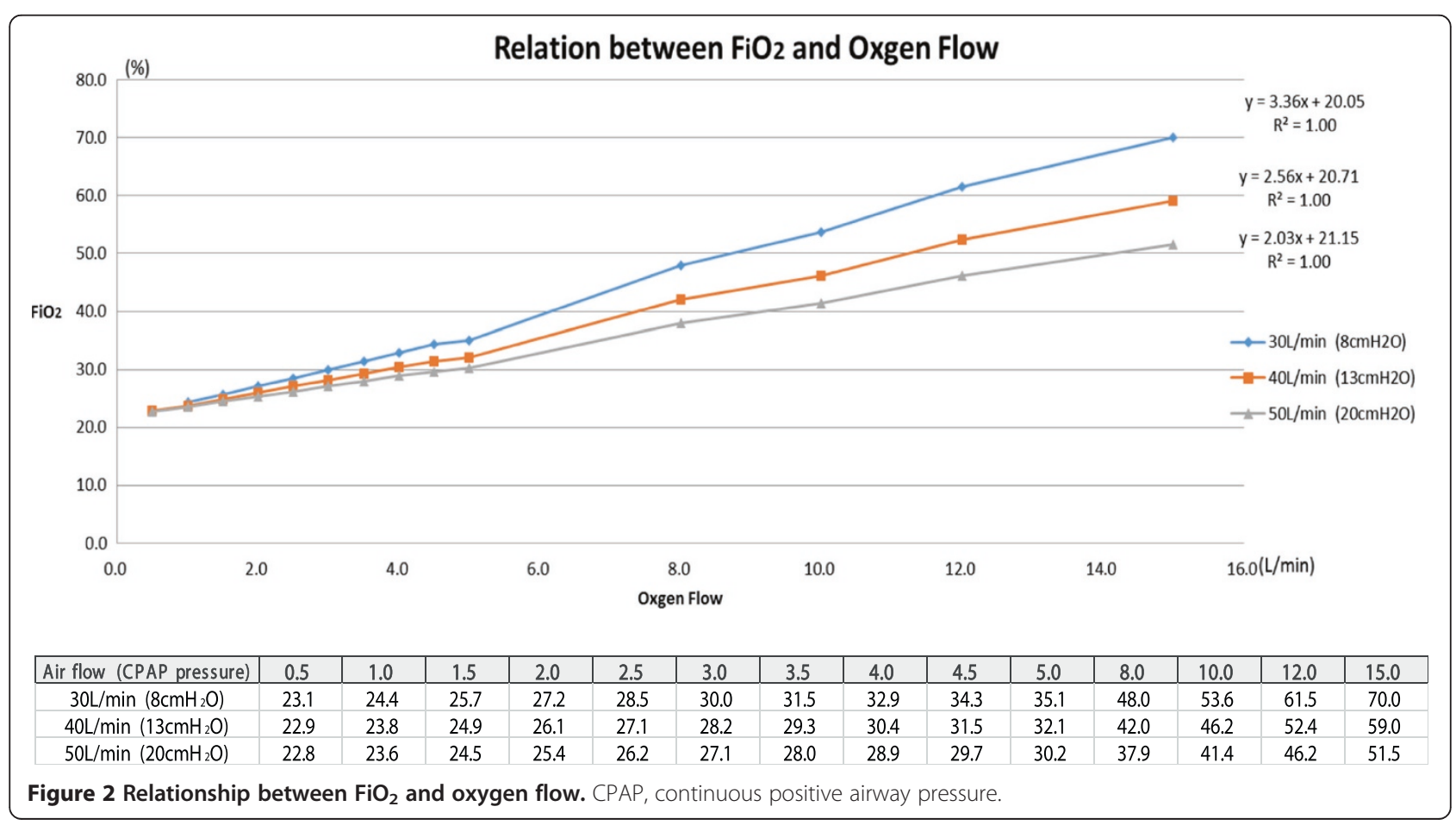


accessory muscles of respiration other than the diaphragm, decreased muscle tone during rapid eye movement (REM) sleep increases alveolar hypoventilation. In addition, factors such as decreased functional reserve capacity, increased upper airway resistance and worsening ventilation-perfusion mismatch result in marked hypoxemia, particularly during REM sleep. This sleep hypoxemia increases pulmonary artery pressure, worsening right-sided heart failure [11]. Furthermore, arrhythmias and polycythemia may develop, increasing the mortality rate [12].

Home NPPV is indicated in patients like ours with a $\mathrm{PaCO}_{2} \geq 55 \mathrm{mmHg}$, persistent nocturnal hypoventilation and cor pulmonale. However, if sleep hypoxemia is present, injudicious oxygen administration without taking SRH into consideration can lead to marked hypercapnia. COPD patients, especially those with pulmonary hypertension, should therefore undergo measurement of nighttime oxygen saturation. If oxygen saturation is decreased, PSG should be performed and an appropriate level of oxygen should be prescribed. Regarding acute exacerbations, Austin et al. conducted a cluster randomized parallel-group trial in 405 patients with presumed acute exacerbation of COPD during ambulance transport, to compare high-flow oxygen therapy with titrated oxygen therapy [12]. The mortality rate was significantly decreased in the titrated oxygen group (4 versus 9\%), and patients in this group with confirmed COPD showed significantly less respiratory acidosis and hypercarbia [12]. With injudicious oxygen administration during sleep, this type of event is likely to recur at night.

Nasal high-flow oxygen therapy essentially requires an oxygen blender. In some settings, such as hospital wards or homes without air supply pipes, an oxygen blender using a Venturi method that can be used with oxygen tubing alone is necessary. This type of set up and oxygen supply is complex. For our patient, we used a modified nasal cannula and PMH-2000 heated humidifier (Pacifico-Medico) and a Vivo 30 ventilator (Breas Medical $A B$ ), without using the Venturi method. This system is quiet and convenient for home use. Continued use at home is possible even in patients with dementia, such as our patient, allowing improvements in $\mathrm{PaCO}_{2}$.

The disadvantage of a NHFOTS is that ventilatory support is not as effective as NPPV. Reports to date have therefore recommended consideration of NPPV or intubated mechanical ventilation if the respiratory rate and oxygenation have not improved within 4 to 6 hours. Further studies evaluating the use of NPPV for respiratory failure in COPD patients involving a larger number of patients are needed $[13,14]$.

\section{Conclusion}

The use of a NHFOTS was effective for delivering a prescribed concentration of oxygen from the time of acute exacerbation until discharge to home in our patient with COPD who also had dementia and SRH. This safe oxygen therapy enabled improvements in sleep-related alveolar hypoventilation. The NHFOTS is currently used as a device to administer high concentrations of oxygen in many patients with type I respiratory failure, but may also be useful instead of a Venturi mask in patients like ours with type II respiratory failure, in addition to providing some PEEP effect.

\section{Consent}

Written informed consent was obtained from the patient for publication of this case report and any accompanying images. A copy of the written consent is available for review by the Editor-in-Chief of this journal.

\section{Abbreviations}

AHI: Apnea-hypopnea index; AVAPS: Average volume-assured pressure support; COPD: Chronic obstructive pulmonary disease; NHFOTS: Nasal high-flow oxygen therapy system; NPPV: Non-invasive positive pressure ventilation; PSG: Polysomnography; SAS: Sleep apnea syndrome;

CPAP: Continuous positive airway pressure; REM: Rapid eye movement; PEEP: positive end-expiratory pressure.

\section{Competing interests}

The authors declare that we have no competing interests.

\section{Authors' contributions}

$\mathrm{MO}, \mathrm{SI}, \mathrm{TN}, \mathrm{TK}$, and KM gathered the information for this case and were major contributors to the writing of the manuscript. YO, MK, NT, TM and TF contributed to writing the 'Discussion' section and editing the manuscript. All authors read and approved the final version of the manuscript.

\section{Acknowledgements}

We acknowledge Pacific-Medico and Breas Medical AB for providing permission to use Figure 1.

\section{Author details}

'Osaka Hospital, Internal Medicine Department, Neyagawakoen 2276-1, Neyagawa City, Osaka 572-0854, Japan. ${ }^{2}$ Osaka Hospital, Surgery Department, Neyagawakoen 2276-1, Neyagawa City, Osaka 572-0854, Japan. ${ }^{3}$ Osaka Hospital, Nursing Department, Neyagawakoen 2276-1, Neyagawa City, Osaka 572-0854, Japan. ${ }^{4}$ Osaka Hospital, Rehabilitation Department, Neyagawakoen 2276-1, Neyagawa City, Osaka 572-0854, Japan. ${ }^{5}$ Okuda Clinic, Internal Medicine, Uchiage1123, Neyagawa, Osaka 572-0858, Japan. ${ }^{6}$ Shinsei Company Limited, Minamiterakatahigashidori 2-9-1, Moriguchi, Osaka 570-0043, Japan. ${ }^{7}$ Chest Company Limited, Hongo 3-25-11, Bunkyoku, Tokyo 113-0033, Japan.

Received: 14 April 2014 Accepted: 31 July 2014

Published: 13 October 2014

\section{References}

1. Scala R, Naldi M, Archinucci I, Coniglio G, Nava S: Noninvasive positive pressure ventilation in patients with acute exacerbations of COPD and varying levels of consciousness. Chest 2005, 128:1657-1666.

2. Laurent Brochard MD, Jordi Mancebo MD, Marc Wysocki MD, Frédéric Lofaso MD, Giorgio Conti MD, Alain Rauss MD, Gérald Simonneau MD, Salvador Benito MD, Alessandro Gasparetto MD, François Lemaire MD, Daniel Isabey PD, Alain Harf MD: Noninvasive ventilation for acute exacerbations of chronic obstructive pulmonary disease. N Engl J Med 1995, 333:817-822.

3. Plant PK, Owen JL, Elliott MW: Early use of non-invasive ventilation for acute exacerbations of chronic obstructive pulmonary disease on general respiratory wards: a multicentre randomised controlled trial. Lancet 2000, 355:1931-1935. 
4. Vestbo J, Hurd SS, Agustí AG, Jones PW, Vogelmeier C, Anzueto A, Barnes PJ, Fabbri LM, Martinez FJ, Nishimura M, Stockley RA, Sin DD, RodriguezRoisin R: Global strategy for the diagnosis, management, and prevention of chronic obstructive pulmonary disease: GOLD executive summary. Am J Respir Crit Care Med 2013, 187(4):347-365.

5. Okuda M, Kashio M, Tanaka N, Fuiji T, Okuda Y: Positive outcome of average volume-assured pressure support mode of a Respironics V60 Ventilator in acute exacerbation of chronic obstructive pulmonary disease. J Med Case Rep 2012, 6:284.

6. Hasani A, Chapman TH, McCool D, Smith RE, Dilworth JP, Agnew JE: Domiciliary humidification improves lung mucociliary clearance in patients with bronchiectasis. Chron Respir Dis 2008, 5:81-86.

7. Ward JJ: High-flow oxygen administration by nasal cannula for adult and perinatal patients. Respir Care 2013, 58:98-122.

8. Parke R, McGuinness S, Eccleston M: Nasal high-flow therapy delivers low level positive airway pressure. Br J Anaesth 2009, 103:886-890.

9. Collop N: Sleep and sleep disorders in chronic obstructive pulmonary disease. Respiration 2010, 80:78-86.

10. Campen MJ, Shimoda LA, O'Donnell CP: Acute and chronic cardiovascular effects of intermittent hypoxia in C57BL/6J mice. J Appl Physiol 2005, 99:2028-2035.

11. Weitzenblum E, Chaouat A: Sleep and chronic obstructive pulmonary disease. Sleep Med Rev 2004, 8:281-294.

12. Austin MA, Wills KE, Blizzard L, Walters EH, Wood-Baker R: Effect of high flow oxygen on mortality in chronic obstructive pulmonary disease patients in prehospital setting: randomised controlled trial. BMJ 2010 341:C5462.

13. Rello J, Pérez M, Roca O, Poulakou G, Souto J, Laborda C, Balcells J, Serra J, Masclans JR, CRIPS investigators: High-flow nasal therapy in adults with severe acute respiratory infection: a cohort study in patients with 2009 influenza A/H1N1v. J Crit Care 2012, 27:434-439.

14. Sztrymf B, Messika J, Bertrand F, Hurel D, Leon R, Dreyfuss D, Ricard JD: Beneficial effects of humidified high flow nasal oxygen in critical care patients: a prospective pilot study. Intensive Care Med 2011, 37:1780-1786.

doi:10.1186/1752-1947-8-341

Cite this article as: Okuda et al:: Nasal high-flow oxygen therapy system for improving sleep-related hypoventilation in chronic obstructive pulmonary disease: a case report. Journal of Medical Case Reports 2014 8:341.

\section{Submit your next manuscript to BioMed Central and take full advantage of:}

- Convenient online submission

- Thorough peer review

- No space constraints or color figure charges

- Immediate publication on acceptance

- Inclusion in PubMed, CAS, Scopus and Google Scholar

- Research which is freely available for redistribution 